\title{
Raman Spectroscopy as a Modern Diagnostic Technology for Study and Indication of Infectious Agents (Review)
}

\author{
DOI: $10.17691 / \mathrm{stm} 2019.11 .4 .19$
}

Received September 26, 2018

B.G. Andryukov, MD, DSc, Leading Researcher, Laboratory of Molecular Microbiology'; Professor, Department of Fundamental Sciences;

A.A. Karpenko, PhD, Senior Researcher, Laboratory of Cell Biophysics; E.V. Matosova, Junior Researcher, Laboratory of Molecular Microbiology"; I.N. Lyapun, PhD, Researcher, Laboratory of Molecular Microbiology ${ }^{1}$

${ }^{1}$ Somov Institute of Epidemiology and Microbiology, 1 Selskaya St., Vladivostok, 690087, Russia; ${ }^{2}$ Far Eastern Federal University, 8 Sukhanova St., Vladivostok, 690091 Russia;

${ }^{3}$ Institute of Marine Biology of the A.V. Zhirmunsky National Scientific Center for Marine Biology, 17 Palchevskogo St., Vladivostok, 690041, Russia

The study and detection of causative agents of infectious diseases are an important and urgent task, the progress of which can be achieved only if different approaches are used. Current diagnostic technologies based on different biophysical detection principles allow the research of complex biological substrates with a high degree of analytical reliability. Raman spectroscopy based on the discovery of molecular structure has long established itself as a reliable analytical tool in various fields of science and technology.

The purpose of this report is to review current achievements in microbiology using the Raman spectroscopy, demonstration its limitations, as well as the most important world trends in the application of this diagnostic technology for the study and indication of pathogens of bacterial and viral infections.

Key words: bacteria; viruses; indication; Raman spectroscopy; modern diagnostic technologies.

\section{Introduction}

Growing bacterial antibiotic resistance causes increasing concern in modern society [1-3]. This problem is of vital importance for global healthcare and its solution demands more rapid and highly sensitive indications of the agents causing bacterial and viral infections [4]. In addition to solving scientific and applied tasks, early and specific diagnosis becomes the most important aspect of the sanitary and epidemiological monitoring, a counteraction to the threats of bioterrorism [5].

An ideal method of detecting infectious agents must include simple stages of sample preparation, provide quick indication of the causative agent, be automated, and relatively inexpensive. Though current methods are considered accurate, they are not sensitive enough and require significant time for pathogen identification [6-9]. For instance, traditional methods of agent indication are based on the gold standard oriented to culturing bacteria in a dense growing media, differentiating them according to the main morphological and biochemical characteristics. The drawbacks of microbiological methods are their high cost; duration (from several days to several weeks) depending on the rate of bacterial cell replication; impossibility to identify the so-called tolerant (dormant) forms of bacteria which do not grow under the conventional conditions (L-forms; viable but nonculturable states; persister cells) and are not detected by routine bacteriological investigations [10-12].

In clinical microbiology, classical methods relying on identification of causative agent properties (morphological, tinctorial, and cultural) are used mainly during agent verification. However, these methods do not take into consideration the phenotypic variations of bacteria which may concern their biological properties and are connected with the conditions of microorganism existence [13-15]. Identification of bacteria with the help of bacteriological analyzers upgrade essentially the accuracy of the traditional microbiological methods but their application requires isolation of pure agent cultures during 18-24 h, expensive equipment, and expendable materials [16-18].

Test-systems based on immunological agent verification are recommended for precise taxonomic identification at the species and intraspecies levels. However, these methods are not direct, their diagnostic value depends on the individual variations of the immune response, and genetic mutations of bacteria. Besides, a relatively narrow diagnostic range is also thought to be a disadvantage as it depends on the availability of antibody spectrum restricting the possibility of their usage for a wide screening of samples [18].

At present, new effective molecular genetic diagnostic tools are being actively implemented in the laboratory

Corresponding author: Boris G. Andryukov, e-mail: andrukov_bg@mail.ru 
practice: multiprimer polymerase chain reaction (PCR), ligase chain reaction based on the detection of sequences of separate conservative regions of microorganism nucleic acids (RNA or DNA) [19-22]. The molecular genetic method possesses an obvious advantage over the classic microbiological methods of causative agent identification providing fast (4-5 h) and accurate indication of the agent with high sensitivity and specificity. Its versatility and probability of identifying both bacterial and viral agents, the capability of investigating small-volume samples, identifying intracellular pathogens and dormant (nonculturable) forms of bacteria are justly referred to the merits of this method [20, 21].

However, in spite of the evident advantages, PCR analysis has some drawbacks too, for example, the possibility to obtain a false-positive result when detecting nucleic acids in nonliving bacterial cells [21, 23]. Inability of this method to differentiate between a viable and nonliving bacteria limits its application for the control of treatment efficacy when it is necessary to perform the tests only after removing dead pathogens from the organism which takes 4-8 weeks [11, 23]. Time- and labor-consuming sample preparation is also a technological weak point of the molecular genetic methods. Besides, mutations of microorganisms in the conservative genome region may lead to false-negative results. Finally, a great number of substances (heparin, EDTA, ethanol, isopropanol, etc.) are able to inhibit polymerase reaction while in the process of PCR samples are at risk of contamination [11, $21,23]$. Practical application of these methods restrains the necessity of buying expensive equipment and dependence on the kit of test-systems [9, 20, 21].

In the last decade, the method of matrix-associated desorption/ionization gains in popularity especially in combination with matrix-assisted laser desorption/ ionization time-of-flight mass spectrometry (MALDI-TOF). This method is based on mass-spectrometric detection of microorganisms by means of laser radiation in order to identify genetically determined specific composition of proteins and lipids of the bacterial cell [11, 24-26]. The existing variations of this method connected with protein (MALDI-TOF MS) or lipid profiling in combination with gas (GC-MS) or liquid chromatography (LC-MS) are becoming increasingly common in medical and sanitaryhygienic investigations including microbiology for prompt (within several minutes), reliable, and effective indication of causative agents of infectious diseases [24]. However, the advantages of MALDI-TOF in speed indication are restricted by the necessity of preliminary isolation of microorganism pure culture from the examined biomaterials, which usually requires no less than 16$24 \mathrm{~h}$, and also procurement of expensive equipment, and destruction of the sample in the course of its analysis [24-26].

Thus, the widely used traditional methods of agent detection have their strong and weak points and limitations [18, 27, 28], therefore, there is a strong necessity in searching for new and effective diagnostic tools for indication of pathogens implying some other biophysical principles of detection. They must combine rapidity, minimal sample preparation, low cost, high sensitivity, and good reproducibility.

In recent years, modern analytical technologies for determining the structure of biological molecules allowing for obtaining information about metabolism of the infectious agents have become the subject of increased attention in biomedical investigations. These diagnostic tools relying on spectroscopy and spectrometry enable a sufficient bulk of information to be derived from a single investigation without sample destruction. Among current biomedical technologies based on early indication of infectious agents owing to their analytical sensitivity and specificity the researchers distinguish Raman scattering spectroscopy (RS) as the most attractive and promising method of indication and verification of causative agents $[9,11,18,23,29]$.

Current achievements in microbiology using RS methods as well as the most important world trends of using this diagnostic technology for exploration and indication of agents causing bacterial and viral infections are presented in this review. The following foreign databases were used as the sources of information: PubMed and Internet Grateful Med v. 2.6, CAB Health, EDINA, and Dialog catalogues covering the period from 2010 till 2018.

\section{Raman scattering and SERS spectroscopy}

This method is based on the phenomenon of resonance Raman (inelastic, combination) scattering of monochromatic light (resonance Raman scattering, RRS) which was discovered by the Indian scientists C.V. Raman and K.S. Krishnan in 1928. Raman spectroscopy uses the Raman effect occurring when the laser beam interacts with a molecular substance [11, 15, 23]. Light filters are used to separate the scattered beams from the obtained light bundle. The scattered beams are amplified and registered in the form of unique set of spectral lines having the frequency other than the incident beam [9, 19, 29]. The scattering spectra are very sensitive to the nature of chemical bonds both in organic molecules and inorganic crystalline lattices. Owing to these properties, Raman inelastic scattering is widely used in chemistry, geology, ecology, materials science, cosmetology, criminology.

In the XXI century, new technologies of enhanced RS proved to be indispensable tools for biomedical scientific and applied investigations due to their main advantages, i.e. being noninvasive, contact-free, requiring no sample preparation, providing high speed of examination, the possibility to work with aqueous buffer solutions, and in combination with confocal, atomic-force, and electronic microscopy $[9,11,23,30,31]$.

The main frequency characteristics observed in the process of investigation with the help of RS are highly specific for various microorganisms and functional groups of intracellular molecules representing a precise 


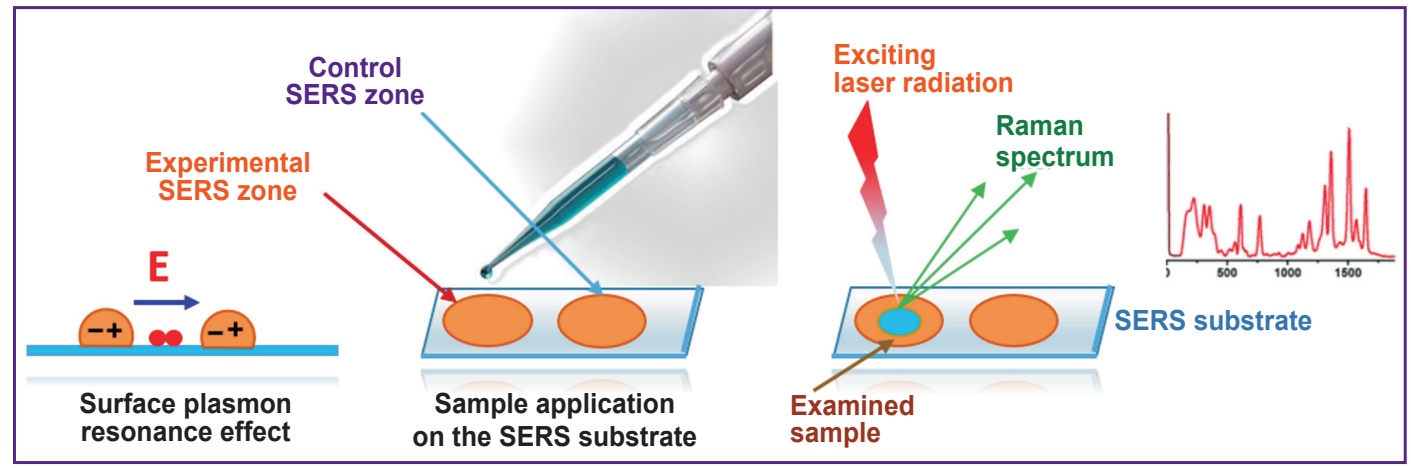

Figure 1. Surface-enhanced Raman spectroscopy - SERS (illustrated by the authors)

individual fingerprint which is capable of providing the inner phenotypic profile of a single cell [32], identifying gene expression [9, 30], compound biosynthesis [18, 31], typical subcellular structures and inclusions [9], physiological states [23, 33], or metabolism changes [28, 29]. This feature made the RS technology very attractive for exploration of different analytes including biological objects. However, low signal intensity at the output was the main reason why this method has not been widely used for so long a time in biomedical researches. And only in 90s years of the last century, when the Raman spectrometer was combined with a confocal microscope, registration of cell spectra, as well as the investigation of very small objects within $1 \mu^{3}$ in size including single cells or their internal fragments, became feasible [18, 28, 34].

A current application of the RS technology in biology is stimulated by the necessity to reduce the lower limit of substance detection to study primarily intracellular biomolecules and microorganisms when solving the tasks of biomedical diagnosis. At the beginning of the XXI century owing to the achievements in nanotechnology, the most powerful technique of signal multiplication, surface-enhanced Raman scattering (SERS), became widely used. This method of the enhanced RS (Figure 1) uses SERS substrates representing highly precise nanostructures with 10$100 \mathrm{~nm}$ nanoparticles of silver and gold sorbed on them in their active zone. The generated plasmons significantly increase the electric field around the metal sharply intensifying the signal (up to $10^{14}$ times) which makes it possible to register vibration states of the intracellular molecules (antibodies, nucleic acids, proteins, lipids) as well as viruses [14, 16, 35, 36]. Therefore, SRES is an analytical tool integrating the specific molecular analysis of RS with the enhancing signal of plasmon nanostructures [37-39]. The acquired spectra are compared with those available in the software database or control spectra of the museum strains.

A special kind of the surface-enhanced RS in which a probe of the scanning probe microscope is used for signal boosting was named tip enhanced Raman scattering (TERS). SERS and TERS variants based on the effect of plasmon resonance received a general name of "giant Raman scattering" and allowed for considerable widening of the RS practical application and recognizing it as an extremely powerful and universal instrument for almost all biological and medical investigations including microbiology (Figure 2) [16, 38, 40, 41].

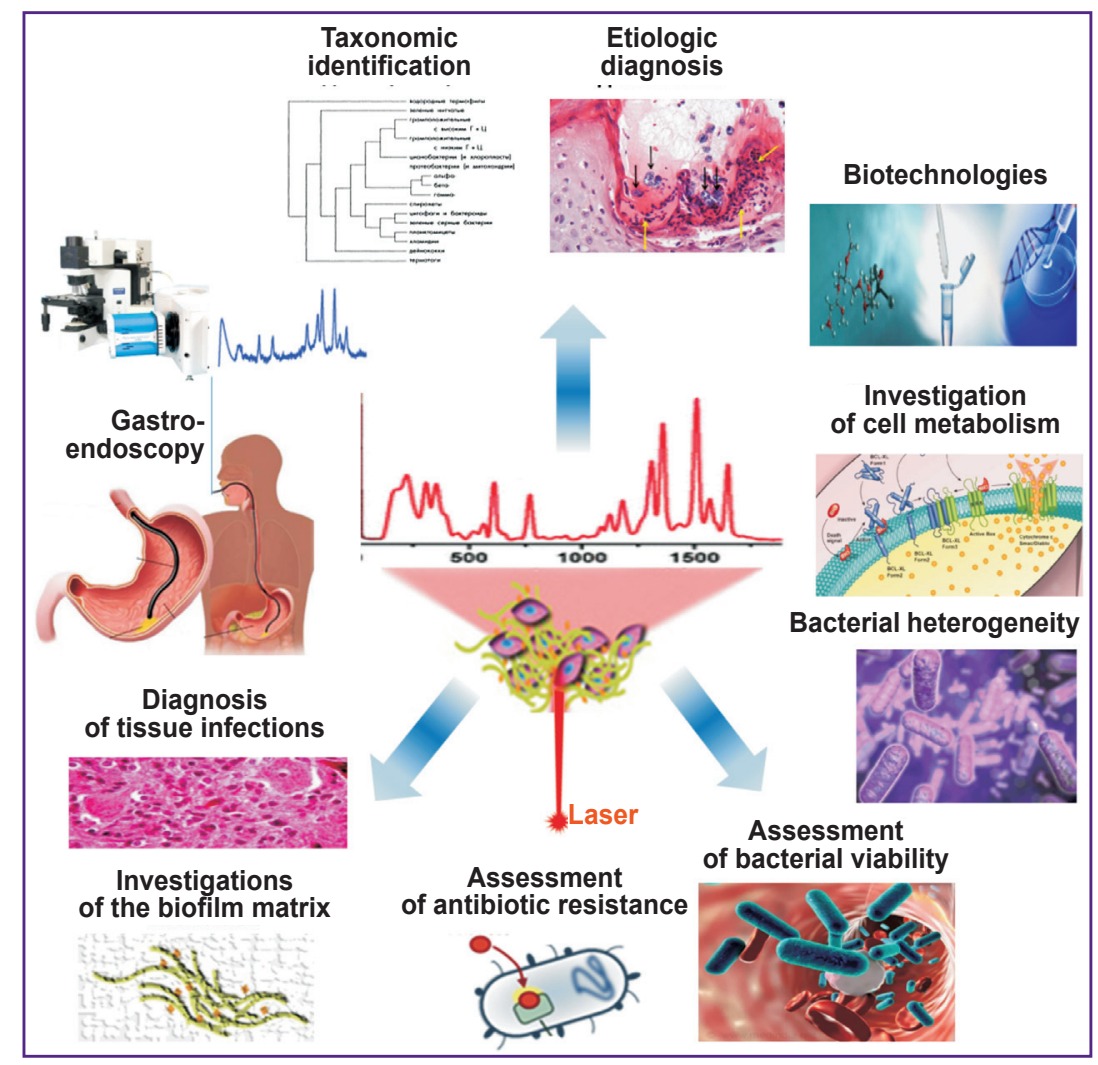

Figure 2. Application of the Raman spectroscopy in microbiology (illustrated by the authors) 
For the last several years, the RS became an indispensable diagnostic tool for the online control of changes in the molecular structure of the bacterial cell on the basis of specific signals from proteins, nucleic acids, lipids, carbohydrates, and inorganic crystals [41]. This technology can be used for detection and indication of microorganisms without sample preparation which makes it a reliable and indispensable method for solving multiple biomedical tasks [9, 11, 23, 41].

For example, RS provides the possibility to assess the intra- and interspecies relations of bacteria. Specific Raman scattering spectra for each type of cells present additional information on their viability, status, differentiation and atypicality, sensitivity to antibiotics $[9,11,42,43]$. During biofilm investigations, RS can detect the main components of extracellular matrix and secondary structures without their destruction which enables the researchers to trace the process dynamics in vitro [19, 44]. Short time of examination (20-40 min), high resolution, simplicity of use make the RS technology and its enhanced modifications perspective diagnostic tool for identification of bacteria and viruses $[9,22,30]$.

\section{RS-compatible methods for bacteria indication}

The renaissance of RS in biomedical researches observed in recent years is connected with the rapidity of obtaining results (minutes) and high specificity of the scattering signal which are the most important characteristics of this method possessing a great potential for detecting and identifying bacteria in a mixed culture. The essential advantage of RS is a vital determination of bacterial biochemical composition with the possibility of their further investigations [19, 22, 30]. As a rule, spectral signatures make it possible to distinguish between gramnegative and gram-positive bacteria as the scattering intensity of the latter is usually higher in all wavelength ranges $[22,30]$.

In recent years, the efficacy of indication, method

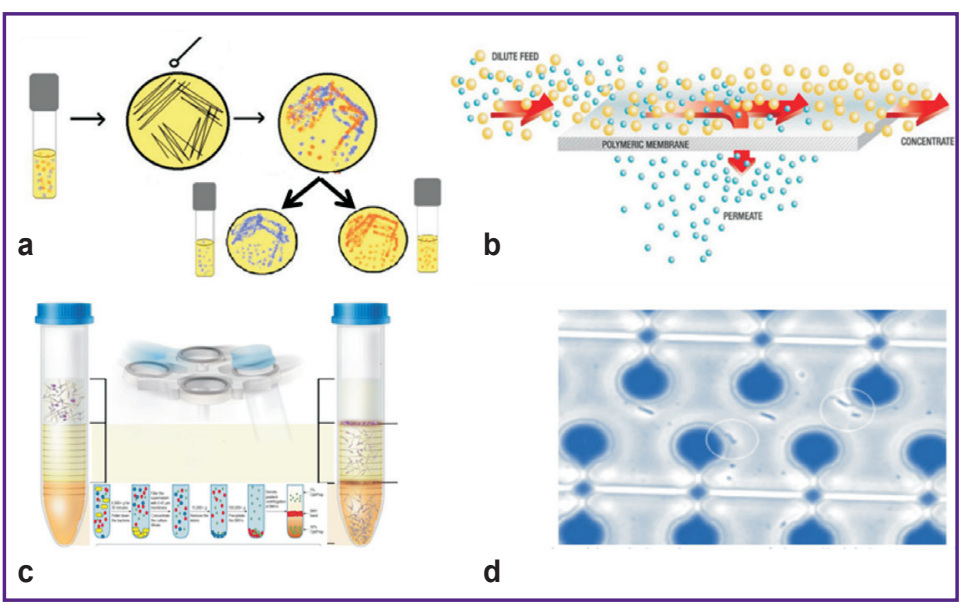

Figure 3. Methods of sample preparation for Raman spectroscopy (illustrated by the authors):

(a) culturing; (b) filtration; (c) differential centrifuging; (d) dielectrophoresis sensitivity, and reproducibility of its results depend to the large extent on the composition of the examined sample and the quantity of the bacteria present in it, while the detection limit is mediated by the strategy of the microbe cell isolation. Therefore, in many publications, various techniques and solutions connected with sample preparation are described in detail [22, 30, 45-47].

Sample preparation. Working out a RS-based strategy of infectious agent indication requires consideration of some aspects concerning sample preparation as it is of crucial importance for gaining optimal results.

Agent culturing with isolation of a pure culture has been recognized to be the best method of sample preparation (Figure $3(a)$ ). Since this process occupies from several to $24 \mathrm{~h}$ and negates the RS merits, the spectroscopic analysis is performed without any preliminary preparation of the sample when working with natural and clinical bacterial isolates. This technology is usually employed in case of bacterial strain typing in retrospective epidemiological investigations of infectious episodes [22, 47, 48]. And the RS method does not yield in informativity to the pulsed field gel electrophoresis which is considered to be a standard method for typing pathogen bacteria [22, 47].

Another method of isolation and purification of the sample is filtration through nanoporous membranes (Figure $3(b)$ ). It is used rather widely in isolation of solid particles from a liquid sample $[45,46,48]$. Bacteria have different sizes usually within $0.5-5 \mu \mathrm{m}$. Since they are substantially smaller than eukaryotic cells, their filtration through the nanoporous membranes provides the necessary enrichment of the sample.

The authors of the works $[49,50]$ have combined filtration of the samples including Salmonella typhimurium, Escherichia coli, and Staphylococcus aureus in the buffered physiological solution using nanoporous membranes containing metal gold or silver nanoparticles labeled with the respective antibodies for SERS spectroscopy. In this case, bacteria bounded to antibodies remained in the membranes whereas unbound bacteria were filtered out. The proposed method allowed the authors not only to differentiate these types of bacteria but to separate the pathogenic strain of $E$. coli $(0157: \mathrm{H} 7)$ from the nonpathogenic $\mathrm{K} 12$ as well. The total indication time was $45 \mathrm{~min}$ and the detection limit was in the range of $10^{2}$ $10^{3} \mathrm{CFU} / \mathrm{ml}$ of the buffer solution [49].

In the present investigations, conjugation of bacteria with specific antibodies labeled with gold or silver nanoparticles is performed before filtration. In a typical experiment, the conjugated bacteria remain on the filter surface after filtration whereas unbound nanoparticles pass through the membrane $[19,30,50]$. The efficacy of this method was achieved by combining sample preparation with the giant Raman scattering, one of the powerful techniques of enhancing the signal of Raman scattering, its SERS or TERS variants $[14,16]$. 
In the work by Chen et al. [50], the entire process of preparing samples of aqueous suspension of $E$. coli cells took 10-20 min depending on the type of filters. The limit of bacteria detection was increased by two orders, to $10^{5} \mathrm{CFU} / \mathrm{ml}$, compared to the use of SERS substrates with silver (gold) nanoparticles without the stage of filtration.

Choosing RS modification one should take into consideration the chemical composition of the examined samples, protein content, concentration of bacterial cells, and presence of contamination. It should be also kept in mind that sample preparation alongside with the correct analysis of the Raman scattering spectra are the key for successful agent identification [19, 22, 30, 45].

Another method of biomolecule detection and sample enrichment is differential centrifuging (Figure 3 (c)). It is usually employed for separating bacterial cells in the solutions with a density gradient at which mass and size of biomolecule are taken into consideration [22].

The second variant of centrifuging depends on the Zeta potential of bacterial cells bound to the nanocomposite structures on the basis of gold (AuNP) and silver (AgNP) nanoparticles and features by a relative easiness of obtaining, stability, and good plasmonic properties [9, 13, 51]. In the studies of Zhou et al. [52], the Raman scattering bacterial signal has been shown to be about 30 times higher using this strategy than in case of employing only mixed bacteria-colloid suspension. The total time of the analysis did not exceed $10 \mathrm{~min}$ and the total volume of reagents necessary for bacterial analysis was as little as $1 \mathrm{ml}$.

In the method of sample concentration based on dielectrophoresis, non-linear electrokinetic phenomena are used for exploration of bacterial surface properties which allows the concentration of bacterial cells even in complex substrates such as blood or urine (Figure 3 (d)). Some researchers have shown that gram-negative and gram-positive bacteria are immobilized on different electric poles due to the differences in the structure and properties of their cell wall [53-56].

Depending on the degree of polarizability of the bacterial cell wall surface as well as the state of the liquid phase, and dilution of the initial sample identification of bacterial agents by the SERS method takes 3-6 min [57-59]. In order to apply this method for bacteriemia diagnosis, it is necessary to inoculate blood for obtaining a higher bacterial concentration (detection limit is about $10^{5} \mathrm{cells} / \mathrm{ml}$ ) [59-61]. Braff et al. [55] have successfully applied a highly sensitive 3D modification of linear dielectrophoresis for separation of Pseudomonas aeruginosa and Streptococcus mitis bacteria at the strain level.

One more method of cell concentration, sorting, and their manipulation is connected with the use of the socalled Raman spectroscopy optical tweezers (RSOT). This method is a well-known variant of RS enabling the increase of Raman scattering intensity due to the longer time of signal accumulation from single molecules or cells in the solution without their sedimentation and fixation [9,
$45,62]$. Previously, the method was used for selective isolation of bacteria from the mixed culture of the yeast cells (Saccharomyces cerevisiae) and two bacterial species (Escherichia coli, Pseudomonas fluorescens) based on their specific scattering spectra with the help of the strongly focused laser beam $[19,44]$.

Pathogen identification. After sample preparation, bacteria become ready for spectroscopic examination. By means of multivariate analysis, even insignificant phenotypic differences between the spectra of bacterial cells can be used for pathogen identification. The software provides the possibility to process sufficiently large data volumes acquired in the course of examination of several independent series. Physiological state of microbial cells or the processing of spectrum parameters may influence the results of identification [63-65].

Reliability of RS identification is based on the qualitative database and statistical algorithms which are applied to the Raman scattering spectra. It is understood that the database supplied with the device contains RS spectra of a huge quantity of genera, species, and strains of microorganisms cultured under ideal conditions (nutrient medium, temperature, time). Therefore, the researcher should create culturing conditions as close to the ideal as possible which may be realized in practice only to a certain degree as the sample composition may be complex, especially when medical tasks are solved, and be different in each individual case [66-68]. The bacterial phase of growth, sample storage conditions, or contamination of the material by heavy metals may influence spectrum variations and the quality of the entire analysis $[3,64,65,69]$. Having obtained a sufficient quantity of scattering spectra, the model is classified and analyzed by the comparison with those contained in the database [3] (Figure 4).

Microbial contamination of the internal body media is one of the main causes of infectious diseases. Exact and quick identification of the causative agents in patients' biosubstrates and the assessment of their sensitivity to antibiotics are of great importance for clinicians [42, $43,70]$. Usually, only one examined bacterial species is present in the sample when scientific researches are conducted. However, in clinical practice, bacteriologists deal commonly with bacterial association when they analyze biosamples, therefore, the task is to identify all pathogens.

Cam et al. [71] were one of the first to demonstrate a successful experience of RS analysis of the samples using SERS substrates. The RS helped identify the composition of bacterial mixture consisting of three different but related bacterial genera: Shigella sonnei, Proteus vulgaris, and Erwinia amylovora and three strains of Escherichia coli (BFK13, BHK7, DH5a).

In the subsequent investigations, it was shown that RS in combination with metal nanoparticles (gold and silver) may be used for the solution of clinical tasks for rapid and specific indication of E. coli (O157:H7), S. aureus, Salmonella spp., Shigella spp., Listeria monocytogenes, 


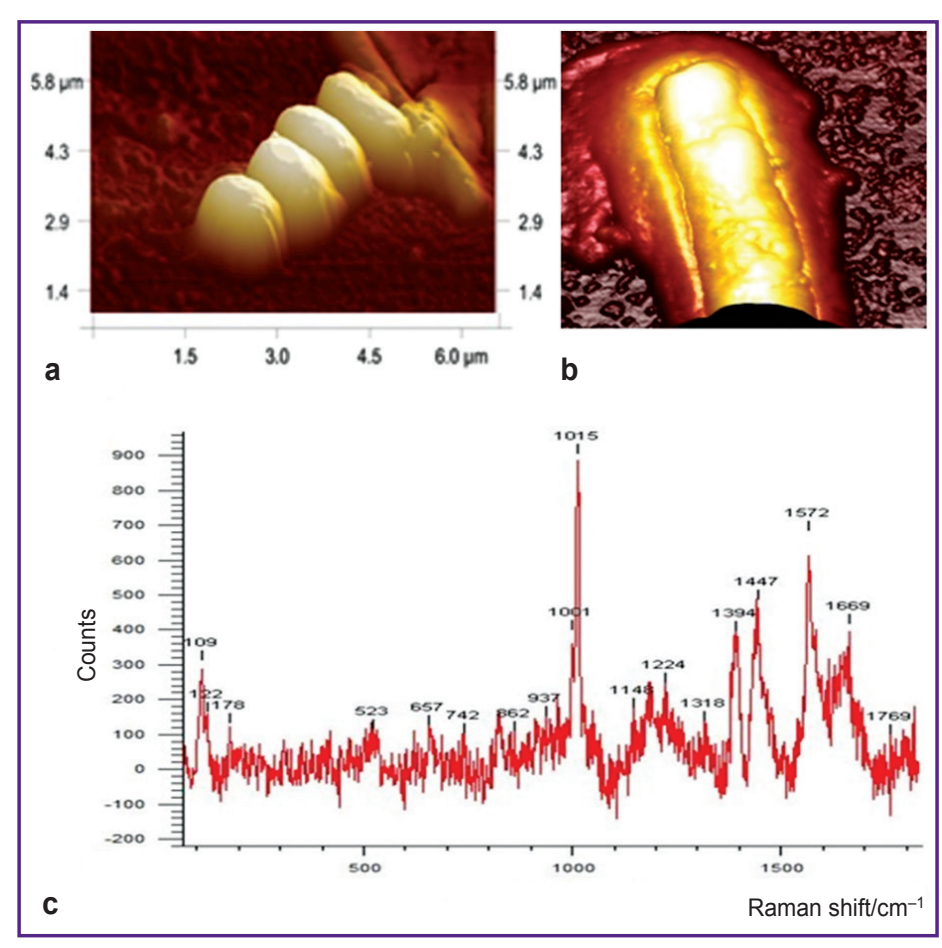

Figure 4. Example of using Raman spectrometry for investigation of the viability of gram-positive Bacillus subtilis bacterium: visualization of the spores (a) and the vegetative form (b) (atomicforce microscopy). Raman spectrum (c) of a single spore detected the biochemical marker of the mature endospore, dipicolinic acid, playing an important role in the bacterial resistance and protection of their DNA against damages (illustrated by A.A. Karpenko)

Enterococcus faecalis, Bacillus spp., and Enterobacter spp. [19, 22, 30, 45, 46]. Aggregation of nanoparticles and bacterial cells provided high intensity of the signal from SERS substrates facilitating the decrease of the agent detection limit to $10^{2} \mathrm{CFU} / \mathrm{ml}$. A complete analysis requires $30 \mathrm{~min}$ [72-75]. Some examples of applying RS for the solution of clinical tasks are given in the Table.

At present, methods using the combination of fiber optic biosensors with RS for supersensitive detection of infectious agents $[30,81]$ are being rapidly evolving since Raman scattering spectra can present a vast array of information on the chemical structure of intrabacterial biomolecules [19, 22].

As the sensitivity of RS depends on the way of sample preparation, biosubstrate properties, and the nanoparticles used a lot of reports have appeared recently on the development of RS-based biosensors including the field and mobile versions of Raman spectrometers for quick and highly effective indication of different bacteria which may be used in expeditions or walking trips [22, 45, 46, 82]. Thus, Chen et al. [46] proposed a mobile biosensor working on the principle of the Ag nanoparticlesenhanced Raman scattering to detect living bacteria in drinking water. Using this biosensor, indication of E. coli, P. aeruginosa, S. aureus (MRSA) strains resistant to methicillin from clinical isolates, and Listeria spp. from food products was successfully done during $5 \mathrm{~min}$ after pretreatment of the water samples with Triton X-100 nonionic detergent. The comparison of spectra enabled the detection and differentiation of two species of Listeria (L. monocytogenes and L. innocua).

Another group of investigators, Wang et al. [83], proposed a portable spectroscopic microfluid biosensor with a high level of sensitivity (110 cells $/ \mathrm{ml}$ ) possessing a subspecies specificity for quick and effective indication and characteristic of Escherichia coli (O157:H7) in water. Monoclonal antibodies with gold nanocrystals were used in this method of indication.

Together with the labeled antibodies, antibiotics interacting specifically with bacterial cellular walls may be used as probes. In 2012, the Taiwan researchers Liu et al. [84] used the technological SERS platform with vancomycin-bound active silver nanoparticles for detection and identification of Staphylococcus aureus, Klebsiella pneumoniae, and Mycobacterium smegmatis in the human blood.

Some examples of applying Raman spectroscopy for the solution of clinical tasks

\begin{tabular}{|c|c|c|c|c|c|}
\hline Sample preparation & Biosubstrates & Pathogens & $\begin{array}{l}\text { Concentration } \\
\text { (CFU/ml) }\end{array}$ & $\begin{array}{l}\text { Investigation } \\
\text { time }\end{array}$ & Reference \\
\hline Filtration & Milk, blood serum & $\begin{array}{l}\text { E. coli } \\
\text { S. aureus (MRSA) }\end{array}$ & $5 \cdot 10^{2}$ & Up to $30 \mathrm{~min}$ & Wang C. et al. [76] \\
\hline Culturing & Synovial fluid & $\begin{array}{l}\text { S. aureus } \\
\text { S. pyogenes }\end{array}$ & $10^{2}-10^{3}$ & $60 \mathrm{~min}$ & Fargasova A. et al. [77] \\
\hline Culturing & Blood serum & S. typhi & $10^{3}$ & $2 \mathrm{~h}$ & Naseer K. et al. [78] \\
\hline $\begin{array}{l}\text { Without sample } \\
\text { preparation }\end{array}$ & Biofilm & Pseudomonas aeruginosa & $10^{3}-10^{4}$ & $1.5 \mathrm{~h}$ & Bodelón G. et al. [79] \\
\hline Centrifuging & Sputum, urine & Mycobacterium tuberculosis & $10^{3}$ & $2 \mathrm{~h}$ & Baron V.O. et al. [42] \\
\hline Centrifuging & Sputum & Klebsiella pneumoniae & $10^{3}-10^{4}$ & $60 \mathrm{~min}$ & Cheong Y. et al. [43] \\
\hline $\begin{array}{l}\text { Without sample } \\
\text { preparation }\end{array}$ & Discharge from urethra & $\begin{array}{l}\text { Chlamydia trachomatis } \\
\text { Neisseria gonorrhoeae }\end{array}$ & $10^{1}-10^{2}$ & $1-1.5 h$ & Chen Y. et al. [80] \\
\hline
\end{tabular}


In the works of Carey et al. [85, 86] it has been shown that with the help of RS it is possible to reveal molecular conformational changes in the bacterial cell after the action of antibiotics (chloramphenicol and meropenem) or hydrogen peroxide. The authors have obtained the data on the quantitative and qualitative intracellular changes in the content of peptides and nucleic acids, they have also performed online in vivo assessment of metabolism by the changes of citrate concentrations in Escherichia coli.

Their Japanese colleagues used the RS scattering to monitor metabolism of Staphylococcus epidermidis which is one of the leading nosocomial pathogens associated with periprosthetic infections of biomedical implants [30, 45]. A metabolic response of bacteria to silicon nitride action in situ has also been investigated. The dynamics of antimicrobial impact and bacterial lysis staging, membrane degradation, and onset of cellular death have been demonstrated [30, 38].

In recent years, interesting results were presented by Chinese and South-Korean researchers about the possibility of using resonance RS in combination with confocal microscopy for examining the changes in the chemical structure of the bacterial biofilms in the process of their generation [22, 46]. Concurrently, all species of bacterial cells included into communities, their metabolism, and signaling protein molecules involved in the competitive interspecies interaction have been verified.

Thus, high analytical characteristics of RS and enhanced modifications of the method (detection rate, sensitivity) make this contact-free technology a valuable and promising diagnostic tool for biomedical investigations. High RS specificity provides valuable information on the phenotype of the microbial cell which in combination with chemometric data makes it possible to identify bacterial species and strains and to determine the level of metabolism and degree of viability. As have already been mentioned, the reliability of indication greatly depends on the quality and completeness of the database. A noninvasive character of RS technology is one more benefit in relation to bacteria detection. Cells remain intact and are ready for further analysis.

\section{RS-compatible methods for indication of viruses}

Using RS, the Japanese scientists Mori et al. [87] have examined protein and amino acid structures of Noroviruslike particles before and after encapsulation into cubic microcrystals. The analysis of spectroscopic data permitted conformation-sensitive Raman bands in viral amino acid constituents to be assigned. The data obtained has opened the possibility to conduct experiments in the field of drug delivery in situ to determine the influence of different preparations on viruses.

The scientists from Pakistan, Khan et al. [88], have studied the possibility of diagnosing viral hepatitis B using RS in combination with the image recognition method. For the experiment, 119 verified serum samples collected from patients infected with viral hepatitis $B$ and delivered from one of the country hospitals have been used. The method was reported to have the diagnostic accuracy of about $98 \%$, sensitivity $100 \%$, and specificity $95 \%$.

Similar investigation has been carried out by Sohail et al. [89] in which a presented diagnostic system used RS for detecting viral hepatitis $\mathrm{C}$. The system demonstrated significant diagnostic power in terms of accuracy, sensitivity, and specificity equal to 95,97 , and $94 \%$, respectively. Viral hepatitis $C$ in the infected patients was verified based on the molecular Raman scattering spectra of blood serum.

The RS method has proved to be so successful as a tool for identification of viral causative agents that it has been suggested to be used as an alternative to traditional methods of verification, for example, solid-phase enzyme immunoassay. The Pakistan researchers Mahmood et al. [29] have successfully tested the RS scattering for indication of Dengue virus as a method for fast screening of blood serum taken from the sick patients. The comparative study has shown that the spectral method in combination with the factor discriminant analysis displayed much higher analytical characteristics $(97.95 \%$ sensitivity, $95.40 \%$ specificity) than the traditional enzyme immunoassay.

Thus, application of various RS modifications in biomedical investigations and microbiology in the last decade proved to be a successful technology for fast and reliable identification of bacteria and viruses. The time necessary for agent detection serves as an important factor and it, according to the data of different researchers, does not exceed $2 \mathrm{~h}$ including sample preparation making the Raman scattering method a perspective diagnostic technique [86, 88, 90, 91].

Being highly specific and sensitive, the RS is able to provide valuable information for the assessment of phenotypic plasticity of the bacterial cell, its metabolic activity, to identify infectious agents down to the genus in the mixed culture. But it should be understood that the reliability of agent identification strongly depends on the quality of the Raman spectra database [86, 87, 92].

The perspectives of further application of the RS method in biomedicine are connected with the analysis automatization and standardization of the operation procedure, on the one hand, and with creation of RSbased mobile and mini-devices permitting investigations at patient's bed-side (in the point-of-care mode) or in field conditions [47, 86, 93].

One more important problem is creation of a vast database considering not only variations of specific Raman spectra for different species and strains of infectious agents but possible phenotypic variants of morphological and metabolic plasticity of bacteria as well.

Solution of the mentioned problems will allow for the application of the RS method for fundamental investigations and in practical medicine as well to detect bacteria and viruses as causative infectious agents. From 
all the above said, we may conclude that RS possesses a great potential especially in combination with the effective strategies of microorganism isolation and modification of the method enabling the enhancement of the Raman scattering signal and investigation of subcellular structures of biological cells.

In this connection one more interesting direction of biomedical application of the RS is worth mentioning. With its help, Russian investigators from Moscow State University in collaboration with their colleagues from Dane and Germany obtained unique information about oxidation-reduction potential and conformations of mitochondrial cytochrome $\mathrm{C}$ which is connected with the efficacy of providing energy to the cells and the development of apoptosis [19, 30, 94]. It took the investigations of these intracellular organelles to a new level. SERS spectra of the living mitochondria placed on the hierarchically structured substrates with silver nanoparticles were found to present exclusive information on the changes in the cytochrome $\mathrm{C}$ molecule structure depending on the alterations of the mitochondrial membrane potential, proton gradient, and ATP synthetase activity [94].

\section{Conclusion}

For the last 5-10 years, Raman spectroscopy attracts greater attention of the specialists in biomedicine. A successful application of the RS for detection of bacteria and viruses has been shown in the present review. Among the cited works, there are numerous confirmations of the fact that experimental and scientific microbiological investigations using spectroscopic tools have entered quickly the diagnostic arsenal of clinical medicine.

In addition to a highly sensitive and fast indication of infectious agents, current RS modifications, giant Raman scattering methods, allow the solution of multiple tasks of molecular microbiology aimed at the study of prokaryote metabolism, their phenotypic, morphological, and metabolic heterogeneity, at the assessment of viability and differentiation of the forms of the programmed bacterial cell death.

In recent years, the biomedical RS methods were evolving in the direction of extending the instrumental base and applied medical investigations. The advent of portable high-resolution laboratory Raman spectrometers designed for highly effective biomedical investigations complete with confocal Raman microscope and software made it possible to analyze the obtained data, select the samples, preprocess and examine the spectra on a realtime basis.

The development of miniature biosensors capable of investigating and measuring different phenomena at the nanoscale level resulted in transformation of diagnostic and treatment methods [95, 96]. In particular, biofunctional Raman nanoparticles were used in vitro and in vivo for nano-sensitization and multiplex diagnosis for the detection of different infectious agents.
Creation of portable variants of miniature Raman spectrometer, professional pocket-size Raman analyzers provided the possibility to carry out highly sensitive microbiological investigations in field conditions [97], at sea [98], Antarctic expeditions [99], space flights [100, 101].

The RS turned out to be an ideal tool for medical investigations in vitro and in vivo for revealing molecular cancer markers [72, 100, 102], atherosclerotic vascular damages [100, 103], narcotic poisoning [104], assessment of nanoparticle biodegradation in the organism, and theranostics of many oncological diseases $[105,106]$. Currently, the RS is being actively used in pharmacology (in studying molecular activity of medicinal preparations and testing their biological activity) [11, 96, 100, 107].

Finally, unique analytical capabilities of the Raman spectroscopy open new approaches for solving the problems of chemical and biological safety. Chinese scientists have proposed to use the SERS technology with gold-coated aluminium substrates for capturing the molecules of phosphororganic toxic substances. This technology is reported to detect these substances at a concentration of $1 \cdot 10^{-9}$ [108]. FLIR Systems, Inc. (USA) included a portable FirstDefender RMX Raman spectrometer (Thermo Scientific, USA) among other devices into the CBRN DR-SKO IDIQ system developed in 2016 and designed to conduct all types of radiation, chemical, biological, and nuclear reconnaissance and which is already being delivered to the U.S. Military Joint Services [109].

A great potential of the Raman spectroscopy is evident but for its maximal realization it needs further development. Among the most perspective directions are extended automation, improvement of reliability, portability, and mobility of the Raman spectrometers. In recent years, a noticeable success is observed in this direction: a number of handheld models for biomedical researches are being currently developed or available in the market (Bio Particle Explorer, rapid, Germany; i-Raman Plus, Italy; SpectraCell RA, river diagnostics, Netherlands).

The next trend is the development and implementation of the standard operating procedure which optimizes the reproduction of the entire chain of stages: from sample selection, sample preparation to the measurement of Raman spectra parameters and chemometric identification of bacteria.

And at last, one more important issue is improvement and completeness of the Raman spectrum databases which must consider phenotypic variations of bacterial physiological state.

Realization of these perspective directions will help further propagation of this modern diagnostic technology in biological scientific investigations and practical medicine.

Study funding. The work was supported by the Complex Program of Fundamental Research of the Far 
East Branch of the Russian Academy of Sciences "The Far East", project No.18-5-099.

Conflicts of interest. The authors have no conflicts of interest to declare.

\section{References}

1. Rai M.K., Deshmukh S.D., Ingle A.P., Gade A.K. Silver nanoparticles: the powerful nanoweapon against multidrugresistant bacteria. J Appl Microbiol 2012; 112(5): 841-852, https://doi.org/10.1111/j.1365-2672.2012.05253.x.

2. Centers for Disease Control and Prevention. Antibiotic resistance threats in the United State, 2013. URL: https://www. cdc.gov/drugresistance/pdf/ar-threats-2013-508.pdf.

3. Pahlow S., Meisel S., Cialla-May D., Weber K., Rösch P., Popp J. Isolation and identification of bacteria by means of Raman spectroscopy. Adv Drug Deliv Rev 2015; 89: 105-120, https://doi.org/10.1016/j.addr.2015.04.006.

4. Morens D.M., Fauci A.S. Emerging infectious diseases: threats to human health and global stability. PLoS Pathog 2013; 9(7): e1003467, https://doi.org/10.1371/journal.ppat.1003467.

5. Suda Y., Chamberlain J., Dowall S.D., Saijo M., Horimoto T., Hewson R., Shimojima M. The development of a novel diagnostic assay that utilizes a pseudotyped vesicular stomatitis virus for the detection of neutralizing activity against Crimean-Congo hemorrhagic fever virus. Jpn J Infect Dis 2018; 71(3): 205-208, https://doi.org/10.7883/yoken. jjid.2017.354.

6. Huang W.E., Griffiths R.I., Thompson I.P., Bailey M.J., Whiteley A.S. Raman microscopic analysis of single microbial cells. Anal Chem 2004; 76(15): 4452-4458, https://doi. org/10.1021/ac049753k.

7. Huang W.E., Li M., Jarvis R.M., Goodacre R., Banwart S.A. Shining light on the microbial world: the application of Raman microspectroscopy. Adv Appl Microbiol 2010; 70: 153-186, https://doi.org/10.1016/s0065-2164(10)70005-8.

8. Patel I.S., Premasiri W.R., Moir D.T., Ziegler L.D. Barcoding bacterial cells: a SERS based methododology for pathogen identification. J Raman Spectrosc 2008; 39: 16601672, https://doi.org/10.1002/jrs.2064.

9. Zhu X., Xu T., Lin Q., Duan Y. Technical development of Raman spectroscopy: from instrumental to advanced combined technologies. Appl Spectrosc Rev 2014; 49(1): 6482, https://doi.org/10.1080/05704928.2013.798801.

10. Popp J., Krafft C., Mayerhöfer T. Modern Raman spectroscopy for biomedical applications. A variety of Raman spectroscopical techniques on the threshold of biomedical applications. Opt Photon 2011; 6(4): 24-28, https://doi. org/10.1002/opph.201190383.

11. Li Y.-S., Church J.S. Raman spectroscopy in the analysis of food and pharmaceutical nanomaterials. J Food Drug Anal 2014; 22(1): 29-48, https://doi.org/10.1016/j. jfda.2014.01.003.

12. Mann T.Z., Haddad L.B., Williams T.R., Read J.S., Dee D.L., Dziuban E.J., Pérez-Padilla J., Jamieson D.J., Honein M.A., Shapiro-Mendoza C.K. Breast milk transmission of flaviviruses in the context of Zika virus: a systematic review. Paediatr Perinat Epidemiol 2018, 32(4): 358-368, https://doi. org/10.1111/ppe.12478.

13. Notingher I. Raman spectroscopy cell-based biosensors. Sensors 2007; 7(8): 1343-1358, https://doi. org/10.3390/s7081343.

14. Efrima S., Zeiri L. Understanding SERS of bacteria.
J Raman Spectrosc 2009; 40(3): 277-288, https://doi. org/10.1002/jrs.2121.

15. Dina N.E., Zhou H., Colniţă A., Leopold N., SzokeNagy T., Coman C., Haisch C. Rapid single-cell detection and identification of pathogens by using surface-enhanced Raman spectroscopy. Analyst 2017; 142(10): 1782-1789, https://doi. org/10.1039/c7an00106a.

16. Premasiri W.R., Moir D.T., Klempner M.S., Krieger N., Jones G., Ziegler L.D. Characterization of the surface enhanced Raman scattering (SERS) of bacteria. J Phys Chem B 2005; 109(1): 312-320, https://doi.org/10.1021/jp040442n.

17. Law J., Ab Mutalib N., Chan K., Lee L. Rapid methods for the detection of foodborne bacterial pathogens: principles, applications, advantages and limitations. Front Microbiol 2015; 5: 770, https://doi.org/10.3389/fmicb.2014.00770.

18. Mosier-Boss P.A. Review on SERS of bacteria. Biosensors 2017; 7(4): 51, https://doi.org/10.3390/bios7040051.

19. Pacheco M.T.T., Moreira L.M. Raman spectroscopy: new perspectives for its clinical application in diagnosis. Photomed Laser Surg 2013; 31(10): 463-465, https://doi. org/10.1089/pho.2013.9873.

20. Wang L., Ye C., Xu H., Aguilar Z.P., Xiong Y., Lai W., Wei H. Development of an SD-PMA-mPCR assay with internal amplification control for rapid and sensitive detection of viable Salmonella spp., Shigella spp. and Staphylococcus aureus in food products. Food Control 2015; 57: 314-320.

21. Sas M.A., Comtet L., Donnet F., Mertens M., Vatansever Z., Tordo N., Pourquier P., Groschup M.H. A novel double-antigen sandwich ELISA for the species-independent detection of Crimean-Congo hemorrhagic fever virus-specific antibodies. Antiviral Res 2018; 151: 24-26, https://doi. org/10.1016/j.antiviral.2018.01.006.

22. Neng J., Li Y., Driscoll A.J., Wilson W.C., Johnson P.A. Detection of multiple pathogens in serum using silicaencapsulated nanotags in a surface-enhanced Raman scattering-based immunoassay. J Agric Food Chem 2018; 66(22): 5707-5712, https://doi.org/10.1021/acs.jafc.8b00026.

23. Schmitt M., Popp J. Raman spectroscopy at the beginning of the twenty-first century. J Raman Spectrosc 2006; 37(1-3): 20-28, https://doi.org/10.1002/jrs.1486.

24. Bocklitz T.W., Crecelius A.C., Matthäus C., Tarcea N., von Eggeling F., Schmitt M., Schubert U.S., Popp J. Deeper understanding of biological tissue: quantitative correlation of MALDI-TOF and Raman imaging. Anal Chem 2013; 85(22): 10829-10834, https://doi.org/10.1021/ac402175c.

25. Bocklitz T.W., Bräutigam K., Urbanek A., Hoffmann F., von Eggeling F., Ernst G., Schmitt M., Schubert U., GuntinasLichius O., Popp J. Novel workflow for combining Raman spectroscopy and MALDI-MSI for tissue based studies. Anal Bioanal Chem 2015; 407(26): 7865-7873, https://doi. org/10.1007/s00216-015-8987-5.

26. Sauget M., Valot B., Bertrand X., Hocquet D. Can MALDI-TOF mass spectrometry reasonably type bacteria? Trends Microbiol 2017; 25(6): 447-455, https://doi. org/10.1016/j.tim.2016.12.006.

27. Cho I.H., Ku S. Current technical approaches for the early detection of foodborne pathogens: challenges and opportunities. Int J Mol Sci 2017; 18: E2078, https://doi. org/10.3390/ijms18102078.

28. Cowan M.K., Bunn J. Microbiology fundamentals: a clinical approach. McGraw-Hill Education; New York, NY, USA; 2016.

29. Mahmood T., Nawaz H., Ditta A., Majeed M.I., 
Hanif M.A., Rashid N., Bhatti H.N., Nargis H.F., Saleem M., Bonnier F., Byrne H.J. Raman spectral analysis for rapid screening of dengue infection. Spectrochim Acta A Mol Biomol Spectrosc 2018; 200: 136-142, https://doi.org/10.1016/j. saa.2018.04.018.

30. Mao Z., Liu Z., Yang J., Han X., Zhao B., Zhao C. In situ semi-quantitative assessment of single-cell viability by resonance Raman spectroscopy. Chem Commun (Camb) 2018; 54(52): 7135-7138, https://doi.org/10.1039/ c8cc01336e.

31. Bergkessel M., Basta D.W., Newman D.K. The physiology of growth arrest: uniting molecular and environmental microbiology. Nat Rev Microbiol 2016; 14(9): 549-562, https://doi.org/10.1038/nrmicro.2016.107.

32. Tao Y., Wang Y., Huang S., Zhu P., Huang W.E., Ling J., $\mathrm{Xu} \mathrm{J}$. Metabolic-activity-based assessment of antimicrobial effects by $\mathrm{D}_{2} \mathrm{O}$-labeled single-cell Raman microspectroscopy. Anal Chem 2017; 89(7): 4108-4115, https://doi.org/10.1021/ acs.analchem.6b05051.

33. Li M.Q., Xu J., Romero-Gonzalez M., Banwart S.A., Huang W.E. Single cell Raman spectroscopy for cell sorting and imaging. Curr Opin Biotechnol 2012; 23(1): 56-63, https:// doi.org/10.1016/j.copbio.2011.11.019.

34. Zhao X., Li M., Xu Z. Detection of foodborne pathogens by surface enhanced Raman spectroscopy. Front Microbiol 2018; 9: 1236, https://doi.org/10.3389/fmicb.2018.01236.

35. Premasiri W.R., Chen Y., Williamson P.M., Bandarage D.C., Pyles C., Ziegler L.D. Rapid urinary tract infection diagnostics by surface-enhanced Raman spectroscopy (SERS): identification and antibiotic susceptibilities. Anal Bioanal Chem 2017; 409(11): 3043-3054, https://doi.org/10.1007/s00216-017-0244-7.

36. Sundaram J., Park B., Kwon Y., Lawrence K.C. Surface enhanced Raman scattering (SERS) with biopolymer encapsulated silver nanosubstrates for rapid detection of foodborne pathogens. Int J Food Microbiol 2013; 1(167): 6773, https://doi.org/10.1016/j.ijfoodmicro.2013.05.013.

37. Cialla-May D., Zheng X.S., Weber K., Popp J. Recent progress in surface-enhanced Raman spectroscopy for biological and biomedical applications: from cells to clinics. Chem Soc Rev 2017; 46: 3945-3961, https://doi.org/10.1039/ c7cs00172j.

38. Kahraman M., Mullen E.R., Korkmaz A., WachsmannHogiu S. Fundamentals and applications of SERS-based bioanalytical sensing. Nanophotonics 2017; 6(5): 831-852, https://doi.org/10.1515/nanoph-2016-0174.

39. Laing S., Jamieson L.E., Faulds K., Graham D. Surfaceenhanced Raman spectroscopy for in vivo biosensing. Nat Rev Chem 2017; 1(8): 0060, https://doi.org/10.1038/s41570-0170060.

40. Hu J., Wang L., Li F., Han Y.L., Lin M., Lu T.J., Xu F. Oligonucleotide-linked gold nanoparticle aggregates for enhanced sensitivity in lateral flow assays. Lab Chip 2013; 13(22): 4352-4357.

41. Banerjee R., Jaiswal A. Recent advances in nanoparticle-based lateral flow immunoassay as a point-ofcare diagnostic tool for infectious agents and diseases. Analyst 2018; 143(9): 1970-1996, https://doi.org/10.1039/c8an00307f.

42. Baron V.O., Chen M., Clark S.O., Williams A., Dholakia K., Gillespie S.H. Detecting phenotypically resistant mycobacterium tuberculosis using wavelength modulated Raman spectroscopy. Methods Mol Biol 2018; 1736: 41-50, https://doi.org/10.1007/978-1-4939-7638-6_4.
43. Cheong Y., Kim Y.J., Kang H., Choi S., Lee H.J. Rapid label-free identification of Klebsiella pneumoniae antibiotic resistant strains by the drop-coating deposition surfaceenhanced Raman scattering method. Spectrochim Acta A Mol Biomol Spectrosc 2017; 183: 53-59, https://doi.org/10.1016/j. saa.2017.04.044.

44. Kallaway C., Almond L.M., Barr H., Wood J., Hutchings J., Kendall C., Stone N. Advances in the clinical application of Raman spectroscopy for cancer diagnostics. Photodiagnosis Photodyn Ther 2013; 10(3): 207-219, https:// doi.org/10.1016/j.pdpdt.2013.01.008.

45. Boschetto F., Adachi T., Horiguchi S., Fainozzi D., Parmigiani F., Marin E., Zhu W., McEntire B., Yamamoto T., Kanamura N., Mazda O., Ohgitani E., Pezzotti G. Monitoring metabolic reactions in Staphylococcus epidermidis exposed to silicon nitride using in situ time-lapse Raman spectroscopy. $J$ Biomed Opt 2018; 23(5): 1-10, https://doi.org/10.1117/1. jbo.23.5.056002.

46. Chen L., Mungroo N., Daikuara L., Neethirajan S. Label-free NIR-SERS discrimination and detection of foodborne bacteria by in situ synthesis of $\mathrm{Ag}$ colloids. J Nanobiotechnology 2015; 13(1): 45, https://doi.org/10.1186/ s12951-015-0106-4.

47. Mungroo N.A., Oliveira G., Neethirajan S. SERS based point-of-care detection of food-borne pathogens. Mikrochim Acta 2016; 183(2): 697-707, https://doi.org/10.1007/s00604015-1698-y.

48. Willemse-Erix D., Bakker-Schut T., SlagboomBax F., Jachtenberg J., Lemmensden N.B., Toom B., Papagiannitsis C.C., Kuntaman K., Puppels G., van Belkum A., Severin J.A., Goessens W., Maquelin K. Rapid typing of extended-spectrum beta-lactamase- and carbapenemaseproducing Escherichia coli and Klebsiella pneumoniae isolates by use of SpectraCell RA. J Clin Microbiol 2012; 50(4): 13701375, https://doi.org/10.1128/jcm.05423-11.

49. Ravindranath S.P., Wang Y., Irudayaraj J. SERS driven cross-platform based multiplex pathogen detection. Sens Actuators B Chem 2011; 152(2): 183-190, https://doi. org/10.1016/j.snb.2010.12.005.

50. Chen J., Wu X., Huang Y.-W., Zhao Y. Detection of E. coli using SERS active filters with silver nanorod array. Sensors Actuators B Chem 2014; 191: 485-490, https://doi. org/10.1016/j.snb.2013.10.038.

51. Halder S., Yadav K.K., Sarkar R., Mukherjee S., Saha P., Haldar S., Karmakar S., Sen T. Alteration of Zeta potential and membrane permeability in bacteria: a study with cationic agents. Springerplus 2015; 4(1): 672, https://doi. org/10.1186/s40064-015-1476-7.

52. Zhou H., Yang D., Ivleva N.P., Mircescu N.E., Niessner R., Haisch C. SERS detection of bacteria in water by in situ coating with Ag nanoparticles. Anal Chem 2014; 86(3): 1525-1533, https://doi.org/10.1021/ac402935p.

53. Beck J.D., Shang L., Li B., Marcus M.S., Hamers R.J. Discrimination between Bacillus species by impedance analysis of individual dielectrophoretically positioned spores. Anal Chem 2008; 80(10): 3757-3761, https://doi.org/10.1021/ ac702113t.

54. Braff W.A., Pignier A., Buie C.R. High sensitivity threedimensional insulator-based dielec-trophoresis. Lab Chip 2012; 12(7): 1327-1331, https://doi.org/10.1039/c2lc21212a.

55. Braff W.A., Willner D., Hugenholtz P., Rabaey K., Buie C.R. Dielectrophoresis-based discrimination of bacteria at the strain level based on their surface properties. PLoS 
One 2013; 8(10): e76751, https://doi.org/10.1371/journal. pone.0076751.

56. Zellner P., Agah M. Silicon insulator-based dielectrophoresis devices for minimized heating effects. Electrophoresis 2012; 33(16): 2498-2507, https://doi. org/10.1002/elps.201100661.

57. Barik A., Cherukulappurath S., Wittenberg N.J., Johnson T.W., Oh S.H. Dielectrophoresis-assisted Raman spectroscopy of intravesicular analytes on metallic pyramids. Anal Chem 2016; 88(3): 1704-1710, https://doi.org/10.1021/ acs.analchem. 5 b03719.

58. Schröder U.C., Ramoji A., Glaser U., Sachse S., Leiterer C., Csaki A., Hübner U., Fritzsche W., Pfister W., Bauer M., Popp J., Neugebauer U. Combined dielectrophoresis-Raman setup for the classification of pathogens recovered from the urinary tract. Anal Chem 2013; 85(22): 10717-10724, https://doi.org/10.1021/ac4021616.

59. Schröder U.C., Bokeloh F., O'Sullivan M., Glaser U., Wolf K., Pfister W., Popp J., Ducrée J., Neugebauer U. Rapid, culture-independent, optical diagnostics of centrifugally captured bacteria from urine samples. Biomicrofluidics 2015; 9(4): 044118, https://doi.org/10.1063/1.4928070.

60. Boardman A.K., Wong W.S., Premasiri W.R., Ziegler L.D., Lee J.C. Rapid detection of bacteria from blood with surface-enhanced Raman spectroscopy. Anal Chem 2016; 88(16): 8026-8035, https://doi.org/10.1021/acs. analchem.6b01273.

61. Sinha S.S., Jones S., Pramanik A., Ray P.C. Nanoarchitecture based SERS for biomolecular fingerprinting and label-free disease markers diagnosis. Acc Chem Res 2016; 49(12): 2725-2735, https://doi.org/10.1021/acs. accounts.6b00384.

62. Baritaux J.C., Simon A.C., Schultz E., Emain C., Laurent P. A study on identification of bacteria in environmental samples using single-cell Raman spectroscopy: feasibility and reference libraries. Environ Sci Pollut Res Int 2016; 23(9): 8184-8191, https://doi. org/10.1007/s11356-015-5953-x.

63. Escoriza M.F., Vanbriesen J.M., Stewart S., Maier J. Studying bacterial metabolic states using Raman spectroscopy. Appl Spectrosc 2006; 60(9): 971-976, https:// doi.org/10.1366/000370206778397290.

64. Walter A., Schumacher W., Bocklitz T., Reinicke M., Rösch P., Kothe E., Popp J. From bulk to single-cell classification of the filamentous growing Streptomyces bacteria by means of Raman spectroscopy. Appl Spectrosc 2011; 65(10): 1116-1125, https://doi.org/10.1366/11-06329.

65. Walter A., Kuhri S., Reinicke M., Bocklitz T., Schumacher W., Rösch P., Merten D., Büchel G., Kothe E., Popp J. Raman spectroscopic detection of Nickel impact on single Streptomyces cells - possible bioindicators for heavy metal contamination. J Raman Spectrosc 2012; 43: 10581064, https://doi.org/10.1002/jrs.3126.

66. Almarashi J.F.M., Kapel N., Wilkinson T.S., Telle H.H. Raman spectroscopy of bacterial species and strains cultivated under reproducible conditions. Spectroscopy 2012; 27: 361365, https://doi.org/10.1155/2012/540490.

67. Qiu W., Xu H., Takalkar S., Gurung A.S., Liu B., Zheng Y., Guo Z., Baloda M., Baryeh K., Liu G. Carbon nanotube-based lateral flow biosensor for sensitive and rapid detection of DNA sequence. Biosens Bioelectron 2015; 64: 367-372, https://doi.org/10.1016/j.bios.2014.09.028.

68. Xu J., Webb I., Poole P., Huang W.E. Label-free discrimination of Rhizobial bacteroids and mutants by singlecell Raman microspectroscopy. Anal Chem 2017; 89(12): 6336-6340, https://doi.org/10.1021/acs.analchem.7b01160.

69. Assaf A., Cordella C.B., Thouand G. Raman spectroscopy applied to the horizontal methods ISO 6579:2002 to identify Salmonella spp. in the food industry. Anal Bioanal Chem 2014; 406(20): 4899-4910, https://doi.org/10.1007/ s00216-014-7909-2.

70. Gilbert N. Four stories of antibacterial breakthroughs. Nature 2018; 555(7695): S5-S7, https://doi.org/10.1038/ d41586-018-02475-3.

71. Cam D., Keseroglu K., Kahraman M., Sahin F., Culha M. Multiplex identification of bacteria in bacterial mixtures with surface-enhanced Raman scattering. J Raman Spectrosc 2010; 41(5): 484-489, https://doi.org/10.1002/jrs.2475.

72. De Pablo J.G., Armistead F.J., Peyman S.A., Bonthron D., Lones M., Smith S., Evans S.D. Biochemical fingerprint of colorectal cancer cell lines using label-free live single-cell Raman spectroscopy. J Raman Spectrosc 2018; 49(8): 1323-1332, https://doi.org/10.1002/jrs.5389.

73. Wang Y., Ravindranath S., Irudayaraj J. Separation and detection of multiple pathogens in a food matrix by magnetic SERS nanoprobes. Anal Bioanal Chem 2011; 399(3): 12711278, https://doi.org/10.1007/s00216-010-4453-6.

74. Wang Y., Song Y., Tao Y., Muhamadali H., Goodacre R., Zhou N.Y., Preston G.M., Xu J., Huang W.E. Reverse and multiple stable isotope probing to study bacterial metabolism and interactions at the single cell level. Anal Chem 2016; 88(19): 9443-9450, https://doi.org/10.1021/acs. analchem.6b01602.

75. Fan Z., Senapati D., Khan S.A., Singh A.K., Hamme A., Yust B., Sardar D., Ray P.C. Popcorn-shaped magnetic coreplasmonic shell multifunctional nanoparticles for the targeted magnetic separation and enrichment, label-free SERS imaging, and photothermal destruction of multidrug-resistant bacteria. Chemistry 2013; 19(8): 2839-2847, https://doi.org/10.1002/ chem.201202948.

76. Wang C., Madiyar F., Yu C., Li J. Detection of extremely low concentration waterborne pathogen using a multiplexing self-referencing SERS microfluidic biosensor. J Biol Eng 2017; 11: 9, https://doi.org/10.1186/s13036-017-0051-x.

77. Fargasova A., Balzerova A., Prucek R., Sedláková M.H., Bogdanova K., Gallo J., Kolar M., Ranc V., Zboril R. Detection of prosthetic joint infection based on magnetically assisted surface enhanced Raman spectroscopy (MA-SERS). Anal Chem 2017; 89(12): 6598-6607, https://doi.org/10.1021/acs. analchem.7b00759.

78. Naseer K., Amin A., Saleem M., Qazi J. Raman spectroscopy based differentiation of typhoid and dengue fever in infected human sera. Spectrochim Acta A Mol Biomol Spectrosc 2018; 206: 197-201, https://doi.org/10.1016/j. saa.2018.08.008.

79. Bodelón G., Montes-García V., Pérez-Juste J., Pastoriza-Santos I. Surface-enhanced Raman scattering spectroscopy for label-free analysis of $\mathrm{P}$. aeruginosa quorum sensing. Front Cell Infect Microbiol 2018; 8: 143, https://doi. org/10.3389/fcimb.2018.00143.

80. Chen Y., Premasiri W.R., Ziegler L.D. Surface enhanced Raman spectroscopy of Chlamydia trachomatis and Neisseria gonorrhoeae for diagnostics, and extra-cellular metabolomics and biochemical monitoring. Sci Rep 2018; 8(1): 5163, https:// doi.org/10.1038/s41598-018-23562-5.

81. Ciobotă V., Burkhardt E.-M., Schumacher W., Rösch P., 
Kusel K., Popp J. The influence of intracellular storage material on bacterial identification by means of Raman spectroscopy. Anal Bioanal Chem 2010; 397: 2929-2937, https://doi. org/10.1007/s00216-010-3895-1.

82. Gao X., Xu H., Baloda M., Gurung A.S., Xu L.-P., Wang T., Zhang X., Liu G. Visual detection of microRNA with lateral flow nucleic acid biosensor. Biosens Bioelectron 2014; 54: 578-584, https://doi.org/10.1016/j.bios.2013.10.055.

83. Wang P., Pang S., Chen J., McLandsborough L., Nugen S.R., Fan M., He L. Label-free mapping of single bacterial cells using surface-enhanced Raman spectroscopy. Analyst 2016; 141(4): 1356-1362, https://doi.org/10.1039/ c5an02175h

84. Liu T.Y., Chen Y., Wang H.H., Huang Y.L., Chao Y.C., Tsai K.T., Cheng W.C., Chuang C.Y., Tsai Y.H., Huang C.Y., Wang D.W., Lin C.H., Wang J.K., Wang Y.L. Differentiation of bacteria cell wall using Raman scattering enhanced by nanoparticle array. J Nanosci Nanotechnol 2012; 12: 50045008, https://doi.org/10.1166/jnn.2012.4941.

85. Carey P.R., Heidari-Torkabadi H. New techniques in antibiotic discovery and resistance: Raman spectroscopy. Ann N Y Acad Sci 2015; 1354(1): 67-81, https://doi.org/10.1111/ nyas.12847.

86. Carey P.R., Whitmer G.R., Yoon M.J., Lombardo M.N., Pusztai-Carey M., Heidari-Torkabadi H., Che T. Measuring drug-induced changes in metabolite populations of live bacteria: real time analysis by Raman spectroscopy. J Phys Chem B 2018; 122(24): 6377-6385, https://doi.org/10.1021/ acs.jpcb.8b03279.

87. Mori H., Oda N., Abe S., Ueno T., Zhu W., Pernstich C., Pezzotti G. Raman spectroscopy insight into Norovirus encapsulation in Bombyx mori cypovirus cubic microcrystals. Spectrochim Acta A Mol Biomol Spectrosc 2018; 203: 19-30, https://doi.org/10.1016/j.saa.2018.05.066.

88. Khan S., Ullah R., Khan A., Ashraf R., Ali H., Bilal M., Saleem M. Analysis of hepatitis B virus infection in blood sera using Raman spectroscopy and machine learning. Photodiagnosis Photodyn Ther 2018; 23: 89-93, https://doi. org/10.1016/j.pdpdt.2018.05.010.

89. Sohail A., Khan S., Ullah R., Qureshi S.A., Bilal M., Khan A. Analysis of hepatitis $C$ infection using Raman spectroscopy and proximity based classification in the transformed domain. Biomed Opt Express 2018; 9(5): 20412055, https://doi.org/10.1364/boe.9.002041.

90. Thomm A.M., Schotthoefer A.M., Dupuis A.P., Kramer L.D., Frost H.M., Fritsche T.R., Harrington Y.A., Knox K.K., Kehl S.C. Development and validation of a serologic test panel for detection of Powassan virus infection in U.S. patients residing in regions where lyme disease is endemic. mSphere 2018; 3(1): e00467-17, https://doi.org/10.1128/ msphere.00467-17.

91. Hoch T., Breton E., Vatansever Z. Dynamic modeling of Crimean Congo hemorrhagic fever virus (CCHFV) spread to test control strategies. J Med Entomol 2018; 55(5): 1124-1132, https://doi.org/10.1093/jme/tjy035.

92. Channon R.B., Yang Y., Feibelman K.M., Geiss B.J., Dandy D.S., Henry C.S. Development of an electrochemical paper-based analytical device for trace detection of virus particles. Anal Chem 2018; 90(12): 7777-7783, https://doi. org/10.1021/acs.analchem.8b02042.

93. Schulze H.G., Rangan S., Piret J.M., Blades M.W., Turner R.F.B. Developing fully automated quality control methods for preprocessing Raman spectra of biomedical and biological samples. Appl Spectrosc 2018; 72(9): 1322-1340, https://doi.org/10.1177/0003702818778031.

94. Brazhe N.A., Evlyukhin A.B., Goodilin E.A., Semenova A.A., Novikov S.M., Bozhevolnyi S.I., Chichkov B.N., Sarycheva A.S., Baizhumanov A.A., Nikelshparg E.I., Deev L.I., Maksimov E.G., Maksimov G.V., Sosnovtseva O. Probing cytochrome $c$ in living mitochondria with surface-enhanced Raman spectroscopy. Sci Rep 2015; 5 : 13793, https://doi.org/10.1038/srep13793.

95. Guo H., Jornet J.M., Gan Q., Sun Z. Cooperative Raman spectroscopy for real-time in vivo nano-biosensing. IEEE Transactions on NanoBioscience 2017; 16(7): 571-584, https://doi.org/10.1109/tnb.2017.2749183.

96. Guo S., Kohler A., Zimmermann B., Heinke R., Stöckel S., Rösch P., Popp J., Bocklitz T. Extended multiplicative signal correction based model transfer for Raman spectroscopy in biological applications. Anal Chem 2018; 90(16): 9787-9795, https://doi.org/10.1021/acs.analchem.8b01536.

97. Lu X., Al-Qadiri H., Lin M., Rasco B. Application of mid-infrared and Raman spectroscopy to the study of bacteria. Food Bioproc Tech 2011; 4(6): 919-935, https://doi. org/10.1007/s11947-011-0516-8.

98. Song Y., Kaster A.K., Vollmers J., Song Y., Davison P.A., Frentrup M., Preston G.M., Thompson I.P., Murrell J.C., Yin H., Hunter C.N., Huang W.E. Single-cell genomics based on Raman sorting reveals novel carotenoid-containing bacteria in the Red Sea. Microb Biotechnol 2017; 10(1): 125-137, https:// doi.org/10.1111/1751-7915.12420.

99. Sansano A., Lopez-Reyes G., Medina J., Rull F. Analysis of arctic carbonates profiles by Raman spectroscopy using exomars Raman laser spectrometer. EPSC Abstracts 2011. URL: https://meetingorganizer.copernicus.org/EPSCDPS2011/EPSC-DPS2011-856-1.pdf.

100. Eberhardt K., Stiebing C., Matthäus C., Schmitt M., Popp J. Advantages and limitations of Raman spectroscopy for molecular diagnostics: an update. Expert Rev Mol Diagn 2015; 15(6): 773-787, https://doi.org/10.1586/14737159.2015.1036744.

101. Jehlička J., Culka A., Nedbalová L. Colonization of snow by microorganisms as revealed using miniature Raman spectrometers-possibilities for detecting carotenoids of psychrophiles on mars? Astrobiology 2016; 16(12): 913-924, https://doi.org/10.1089/ast.2016.1487.

102. Jenkins C.A., Lewis P.D., Dunstan P.R., Harris D.A. Role of Raman spectroscopy and surface enhanced Raman spectroscopy in colorectal cancer. World J Gastrointest Oncol 2016; 8(5): 427-438, https://doi.org/10.4251/wjgo.v8.i5.427.

103. Kochan K., Marzec K.M., Chruszcz-Lipska K., Jasztal A., Maslak E., Musiolik H., Chłopicki S., Baranska M. Pathological changes in the biochemical profile of the liver in atherosclerosis and diabetes assessed by Raman spectroscopy. Analyst 2013; 138(14): 3885-3890, https://doi. org/10.1039/c3an00216k.

104. Neugebauer U., Rösch P., Popp J. Raman spectroscopy towards clinical application: drug monitoring and pathogen identification. Int $J$ Antimicrob Agents 2015; 46: S35-S39, https://doi.org/10.1016/j. ijantimicag.2015.10.014.

105. Tolstik E., Osminkina L.A., Matthäus C., Burkhardt M., Tsurikov K.E., Natashina U.A., Timoshenko V.Y., Heintzmann R., Popp J., Sivakov V. Studies of silicon nanoparticles uptake and biodegradation in cancer cells by Raman spectroscopy. Nanomedicine 2016; 12(7): 1931-1940, https://doi.org/10.1016/j.nano.2016.04.004. 
106. Mehta H.H., Prater A.G., Shamoo Y. Using experimental evolution to identify druggable targets that could inhibit the evolution of antimicrobial resistance. J Antibiot (Tokyo) 2018; 71(2): 279-286, https://doi.org/10.1038/ja.2017.108.

107. Gala U., Chauhan H. Principles and applications of Raman spectroscopy in pharmaceutical drug discovery and development. Expert Opin Drug Discov 2015; 10(2): 187-206, https://doi.org/10.1517/17460441.2015.981522.
108. Zhao Q., Liu G., Zhang H., Zhou F., Li Y., Cai W. SERS-based ultrasensitive detection of organophosphorus nerve agents via substrate's surface modification. J Hazard Mater 2017; 324(Pt B): 194-202, https://doi.org/10.1016/j. jhazmat.2016.10.049.

109. American security today: Informational Internetportal. URL: https://americansecuritytoday.com/flir-receives54-2m-order-us-dod-dr-sko-systems/. 